\title{
Drilling and Completion Challenges in Fault Zones: Lessons Learned from ICDP Projects
}

by Bernhard Prevedel

\section{Introduction}

Scientific drilling projects conducted within the framework of the International Continental Scientific Drilling Program (ICDP) and the German Continental Deep Drilling Program (KTB) represent important milestones in fault zone (FZ) drilling. This abstract intends to highlight the technical problems and potential solution pathways in such drilling programs as well as their business implications in today's hydrocarbon hype. Special attention will be paid to the fact that scientific wells today are no longer seen as pure drilling events, but rather as long-term downhole observatory installations, requiring specialized completion technology and advanced planning before drilling.

\section{Lessons from the KTB and ICDP Projects}

During the $9.1 \mathrm{~km}$ ultra deep KTB drilling program in Germany several fault zones in the drilled amphibolite facies crystalline rock suite were truncated. Severe drilling problems occurred primarily at a depth between 6.9 and 7.3 $\mathrm{km}$ depth in a main fault zone characterized by cataclasis, secondary mineralization, fluid inflow and a pronounced seismic reflectivity of the whole steeply dipping fault zone. Main contributors to the difficulties were stress-induced breakouts that increased rapidly with time especially in the central part of the fault to up to ten times the nominal drilled volume, as observed through repeated caliper logs. The other factor creating drilling setbacks were caliper reduction in a zone consisting of chlorite gneisses at $8300 \mathrm{~m}$ depth. Both issues finally made additional cementing, sidetrack drilling, or protracted casing setting necessary, and led to a time loss and a cost overrun of approximately $20 \%$.

Similar breakout phenomena were observed in the drilling of main hole of the San Andreas Fault Zone Observatory at Depth (SAFOD), where the 8 "hole section developed caveouts of 20 " and more in the lower 60 degree deviated section of the well from approximately 3.0 to $4.0 \mathrm{~km}$, a depth range where the active trace of the San Andreas Fault is suspected.

Another observation during the drilling of fault zones is sudden changes in formation fluid pressure. For example, during the drilling of the 1000-m-deep Corinth borehole, a pressure surge of approximately 10 bars was observed at a depth of $760 \mathrm{~m}$ when penetrating the fault.
A selection of the most important lessons learned from previous drilling efforts in fault zones includes; 1) careful planning with multi-disciplinary industry and academia advisory panels is necessary, including extended well-bore stability planning; 2) use of a top drive plus vertical steering system with downhole motors is advised, to ensure operational speed and precision in drilling, and also in logging (including use of downhole MWD/LWD systems); 3) expandable casings or casing-drilling systems for loose and unstable formations or extended casing scheme with additional casings needs to be planned beforehand; 4) enhanced pumping and mud carrying capacity of the drilling mud to balance under- or overpressures is necessary; 5) wireline coring techniques for successful and rapid sample gain are advantageous; 6) synergy between research drilling projects and programs need to be developed; and 7) designs of scientific wells for life are necessary.

The last point represents a significant paradigm change from the way we regarded scientific well drilling in the past. Today such wells are planned and designed for long life, involving permanent monitoring arrays and completion technologies, very similar to the ones employed in the oil and gas industry.

\section{Downhole Observatories}

Completion technology is a term from the oil field industry that stands for the equipment installed in a well after the drilling phase, enabling the production of either (i) hydrocarbons in oil and gas or (ii) the acquisition of data from research wells. Although the objectives are different, the equipment designs and investment efforts are almost the same.

Long-term downhole data acquisition today is ensured from completed scientific wells by means of permanent monitoring technology. They can in principle be categorized in two basic embodiments:

Type-1: Outside the casing cemented cables and sensors (outside casing arrays = OCA), which are primarily based on (i) fiber-optic sensors and cables for distributed temperature, pressure, rock strain and acceleration measurements, as well as (ii) analogue sensors on copper cables for electric conductivity, seismic and pressure measurements. 
The main characteristics for this entirely analogue sensor technology are the requirement for a pressure-isolating wellhead outlet design, its system ruggedness combined with highest redundancy and no external power requirement.

Type-2: Inside the casing semi-permanently installed tools (inside casing arrays = ICA), which are instruments run primarily on fiber/electrical armoured cable, like digital 3-component seismometer, tiltmeter, accelerometer and other logging equivalent sensors.

Main features of this primarily digital technology are its persistent problems of cable survival in long-term deployments, sensitivity to gas attack on elastomers, poor sensor coupling to the borehole wall, limited overall system redundancy, but good stability of the sensors in a high temperature environment.

\section{Present Drilling Market}

One key indicator of today's market development is the utilization of the worldwide rig fleet, both for marine and land drilling units. Their day-rates rose since 1994 by a factor of six to seven, with a rig utilization today consistently hitting $100 \%$. As with rig rates, the service industry increased prices recently for equipment and services and further tightened delivery conditions. On an average, prices rose $+18 \%$ in the last 6 months and delivery times for critical well equipment increased from half a year to one year and in some instances even to 17 months.

Due to the lack of drilling equipment suitable for scientific drilling and coring, the GFZ (GeoForschungsZentrum) Potsdam has decided to design and invest in its own proprietary scientific drilling rig, named Innova Rig. This totally new and fully hydraulic rig concept, built by a tunnel bore manufacturing works in southern Germany will be delivered

Table 1. Technical specifications of Innova Rig:

\begin{tabular}{|l|l|}
\hline Drilling depth & $3500-5000 \mathrm{~m}$ \\
\hline Regular hook-load & $3500 \mathrm{kN}$ \\
\hline Nominal rotary speed & $220 \mathrm{rpm}$ (max.) \\
\hline Rotary torque & $40-75 \mathrm{kNm}$ \\
\hline Wire-line coring speed & $500 \mathrm{rpm}$ (max.) \\
\hline Wire-line coring torque & $12-18 \mathrm{kNm}$ \\
\hline Tripping speed & $500 \mathrm{~m} / \mathrm{hr}$ \\
\hline Hoist cylinder stroke & $22 \mathrm{~m}$ \\
\hline Drive power upper limit & $4000 \mathrm{~kW}$ \\
\hline Rid weight (approx.) & $370 \mathrm{tons}$ \\
\hline Mud pumps & $3 \times 1000 \mathrm{~kW}$ \\
\hline WL coring pump & $1 \times 350 \mathrm{~kW}$ \\
\hline Mud pressure & $350 \mathrm{bar}(\mathrm{max})$. \\
\hline Mud tank system & $240 \mathrm{~m}$ \\
\hline General set & $3 \times 1540 \mathrm{kVA}$ \\
\hline Rack capacity & $>7000 \mathrm{~m}$ \\
\hline Wire-line coring winch & $5500 \mathrm{~m}$ \\
\hline Coring line & $\mathrm{d}=12.7 \mathrm{~mm}$ \\
\hline
\end{tabular}

by the end of 2007 . The rig will be operated by a joint industry cooperation company for the drilling of both commercial as well as research projects. GFZ will be the owner of the rig while the drilling contractor partner will be in charge of staffing and daily operations.

The technical highlights of Innova Rig will be its special hybrid rig design and on-board equipment aiming especially at scientific drilling and integrating well proven drilling techniques around a variable application of rotary drilling and coring with the least possible environmental impact. Based on its container-module design, the hook-load will be directly supported by substructure, and rig moves will be greatly reduced in time due to optimized modular truck loads.

The entire energy management of all rig modules is designed form a holistic viewpoint, with highest safety standards due to full automation, integrated noise attenuation design and reduced footprint of the entire drill site. The hoist and feed system are fully hydraulic (no drilling line), constructed to handle doubles including a pipe manipulator to store the tubulars outside the rig on the pipe rack including a torque unit on the catwalk. (See Table 1.)

With this equipment planned, built, and operated for science, a land equivalent to the Integrated Ocean Drilling Program (IODP) research drilling vessels will be at hand for research projects and increase efficiency and hence reduce the high costs of such endeavors. Due to the dual-use concept in industry and academia however, the Innova Rig can be set aside for commercial industry operations and therefore maximize rig utilization and return of investment.

\section{Concluding Remarks}

Fault-zone and seismogenic zone drilling projects are complex and must be considered in their planning as well as operation phase as high-tier drilling operations. Due to the present boom in hydrocarbon and mineral exploration, the existing drilling equipment is very short in supply and quite expensive. The special engineering and equipment needs for scientific fault-zone drilling and monitoring instrumentation are not available off the shelf. Therefore, an extended close communication and interaction with research and industry experts are crucial. The establishment of advisory panels, the enhancement of exchange between IODP and ICDP and the joint development of procedures and engineering processes will be important steps to ensure safe fault-zone drilling and stable long-term monitoring observatories at depth in the future.

\section{Author}

Bernhard Prevedel, ICDP/OSG (Operational Support Group), GFZ-Potsdam, Telegrafenberg A34, D-14473, Potsdam, Germany, e-mail: prevedel@gfz-potsdam.de. 